\title{
Editorial
}

\section{Subspeciality in Private Teaching Hospital}

\author{
Dr. G..C. Das
}

Professor and HOD of Nephrology, College of Medical Sciences, Bharatpur, Nepal,

The Medical science is improving day by day with a basic need of all subspeciality wings like- Cardiology, Neurology, Nephrology, Cardiothoracic surgery, Urology, Neurosurgery. Likewise in a developing country like Nepal, there is a greater demand of subspeciality hospital- the example being CMS-TH, Bharatpur the first subspeciality Medical College Teaching Hospital in the whole of Nepal. Nephrology being an indispensible subspeciality Department with OPD and indoor facilities along with hemodialysis and Peritoneal dialysis setup, it has already been started since January 2010 with provision of giving Subspeciality DM Nephrology training programme under the pioneership of the undersigned. Likewise DM Cardiology, DM Neurology, Mch Cardiothoracic Surgery and Urology also have been started simultaneously.

The awareness of the citizens in whole of Nepal is now slowly increasing regarding kidney diseases and Nephrology department. This will cater services in full swing to the ailing community of the society especially when there is a higher prevalence of Diabetes Mellitus, Hypertension and chronic drug abuse including analgesic nephropathy or chronic alcoholism in the community.

The need of Hemodialytic support becomes a dire necessity especially for Road Traffic Accident patients, ICU/ITU patients and all Acute kidney injury and CKD patients.

The dramatic result of the dialytic support is ever encouraging and magic like which is the flying wing of Nephrology department of this esteemed Institution.

However we pray the Almighty to give us full strength and blessings for rapid and quicker improvement of all subspeciality departments with a future additional setup of Kidney Transplantation programme.

The institute is already marching forward with a rapid development of Nephrology department for the wider services to the entire Nepal community. Let Nephrology department and other higher specialities in Nepal long live-long live. 